\title{
Mechanical and Magnetic Properties of Double Layered Nanostructures of Tin and Zirconium Oxides Grown by Atomic Layer Deposition
}

\author{
Aile Tamm ${ }^{1, * \mathbb{C}}$, Helle-Mai Piirsoo ${ }^{1}$, Taivo Jõgiaas ${ }^{1}$, Aivar Tarre ${ }^{1} \mathbb{(}$, Joosep Link ${ }^{2}$, Raivo Stern ${ }^{2} \mathbb{D}$ \\ and Kaupo Kukli ${ }^{1}$ (D) \\ 1 Institute of Physics, University of Tartu, W. Ostwaldi 1, 50411 Tartu, Estonia; \\ helle-mai.piirsoo@ut.ee (H.-M.P.); taivo.jogiaas@ut.ee (T.J.); aivar.tarre@ut.ee (A.T.); kaupo.kukli@ut.ee (K.K.) \\ 2 Laboratory of Chemical Physics, National Institute of Chemical Physics and Biophysics, Akadeemia tee 23, \\ 12618 Tallinn, Estonia; joosep.link@kbfi.ee (J.L.); raivo.stern@kbfi.ee (R.S.) \\ * Correspondence: aile.tamm@ut.ee; Tel.: +372-737-4662
}

check for updates

Citation: Tamm, A.; Piirsoo, H.-M.; Jõgiaas, T.; Tarre, A.; Link, J.; Stern, R.; Kukli, K. Mechanical and Magnetic Properties of Double Layered Nanostructures of Tin and Zirconium Oxides Grown by Atomic Layer Deposition. Nanomaterials 2021, 11, 1633. https://doi.org/10.3390/ nano11071633

Academic Editor: Yurii K. Gun'ko

Received: 21 May 2021

Accepted: 18 June 2021

Published: 22 June 2021

Publisher's Note: MDPI stays neutral with regard to jurisdictional claims in published maps and institutional affiliations.

Copyright: (c) 2021 by the authors. Licensee MDPI, Basel, Switzerland. This article is an open access article distributed under the terms and conditions of the Creative Commons Attribution (CC BY) license (https:/ / creativecommons.org/licenses/by/ $4.0 /)$.

\begin{abstract}
Double layered stacks of $\mathrm{ZrO}_{2}$ and $\mathrm{SnO}_{2}$ films, aiming at the synthesis of thin magnetic and elastic material layers, were grown by atomic layer deposition to thicknesses in the range of 20-25 nm at $300{ }^{\circ} \mathrm{C}$ from $\mathrm{ZrCl}_{4}, \mathrm{SnI}_{4}, \mathrm{H}_{2} \mathrm{O}$, and $\mathrm{O}_{3}$ as precursors. The as-deposited nanostructures consisted of a metastable tetragonal polymorph of $\mathrm{ZrO}_{2}$, and a stable tetragonal phase of $\mathrm{SnO}_{2}$, with complementary minor reflections from the orthorhombic polymorph of $\mathrm{SnO}_{2}$. The hardness and elastic modulus of the stacks depended on the order of the constituent oxide films, reaching 15 and $171 \mathrm{GPa}$, respectively, in the case of top $\mathrm{SnO}_{2}$ layers. Nonlinear saturative magnetization could be induced in the stacks with coercive fields up to 130 Oe.
\end{abstract}

Keywords: atomic layer deposition; nanostructures; magnetization; nanoindentation; tin dioxide; zirconium dioxide

\section{Introduction}

Magnetic thin solid films can be of interest as functional materials tailoring different physical properties such as ferromagnetism as well as mechanical elasticity [1,2]. The ability to adjust the magnetic properties of a system without drastically changing other physical properties, such as electrical, mechanical, or thermal properties, could be beneficial for applications in magnetic micro- and nanoelectromechanical systems [3]. In addition, electrodeposited soft magnetic materials are used as writing heads for hard disks, where the main requirements include corrosion resistance, low stress, and high thermal stability [4]. One might seek materials systems with high corrosion resistance, mechanical hardness, and elasticity, at the same time using materials of higher transparency. Some alloys of metals can be regarded as materials simultaneously exhibiting magnetism and elasticity. Complementarily, optical transparency may herewith be achieved if the films would possess nanocrystalline nature [1]. Magnetization performance may in such materials become directly affected by local changes in mechanical strain and stress [5-7]. In this regard, nanoindentation studies on hardness and elasticity are relevant, especially when considering the materials for applications like magnetic recording, where mechanical properties of the recording medium and reading head surface become important. Magnetic thin films are often based on metallic thin films like Fe, $\mathrm{Ta}, \mathrm{Co}$, or $\mathrm{Cr}$ [8] and are less based on oxides. On some occasions, the thin film thickness is kept relatively high at $600 \mathrm{~nm}$ [9] to avoid any influence from deposition substrate on thin-film properties during nanomechanical characterization. On the other hand, some publications report the magnetic and mechanical properties of thin films with thicknesses around $70 \mathrm{~nm}$ [8]. In the latter article, the authors admit that to measure directly only the thin film properties, they should be able to measure properties at a nanoindenter tip displacement of $7 \mathrm{~nm}$ or below to avoid 
substrate influence and this task probably cannot be fulfilled. Due to developments in measurement techniques and technology in recent years, the possibility to mechanically characterize ultra-thin films on a substrate has almost become a viable option $[1-3,5,7]$.

Transparent conducting magnetic semiconductors, e.g., bismuth-doped $\mathrm{ZnO}$ [10] can be considered as alternatives to metal alloys. Further, accommodation of wide band-gap transition metal oxides, i.e., insulators, instead of metals and semiconductors might more feasibly provide high transparency in the visual range, whereby the nonlinear magnetization in such oxides could be achieved by the engineering of their dimensions and, concurrently, their phase composition. Synthesis processes of metal oxides might also be considered as relatively inexpensive and more robust, compared to those of heavy and noble metals, in addition to their compatibility to a large area and low-temperature deposition techniques, such as atomic layer deposition (ALD). One might expect the formation and presence of metastable polymorphs, possessing useful physical properties, in nanocomposites of different metal oxides, such as, for example, $\mathrm{SnO}_{2}$ and $\mathrm{ZrO}_{2} . \mathrm{SnO}_{2}$ is a transparent, wide-band-gap oxide semiconductor that is applied widely in many fields of oxide electronics [11,12], owing to its good optical and electrical properties and excellent chemical and thermal stability [13].

Mixtures of $\mathrm{SnO}_{2}$ and $\mathrm{ZrO}_{2}$ in thin-film form, obtained by pulsed laser deposition, have performed as transparent conductors [14]. Optically fully transparent stacks of sol-gel synthesized $\mathrm{ZrO}_{2}$ and $\mathrm{SnO}_{2}$ films have been studied as gate dielectrics on channel layers, respectively, in transistor devices [15]. Tin-rich transparent mixtures of $\mathrm{SnO}_{2}$ and $\mathrm{ZrO}_{2}$, synthesized by chemical solution deposition, have demonstrated nonlinear saturative magnetization, increasing with the content of zirconium, under an external magnetic field [16].

One could propose deposition and engineering of nanocomposite material layers in stacks, instead of mixtures, in order to provide constituent functional metal oxides of distinct composition and controlled structure. In this way, the formation (ordering) of possible phases would more likely be defined either by the influence of the structure of substrates or the thickness of the films limiting the crystal growth, instead of the cation ratio in mixtures.

The present study has been devoted to the synthesis of $\mathrm{ZrO}_{2}$ and $\mathrm{SnO}_{2}$ thin films in stacked layers by ALD. The precursor chemistry was based on ALD processes using $\mathrm{ZrCl}_{4}$ and $\mathrm{H}_{2} \mathrm{O}$ [17], and $\mathrm{SnI}_{4}$ and $\mathrm{O}_{3}$ [18] as precursors. The investigations compared the evaluation of the crystallographic phase composition, vibrating sample magnetometry, and instrumented nanoindentation.

\section{Materials and Methods}

The films were grown in a flow-type in-house-built hot-wall ALD reactor [19] from tin(IV)iodide ( $\mathrm{SnI}_{4}, 95 \%$, Sigma Aldrich, Darmstadt, Germany) and zirconium(IV)chloride ( $\mathrm{ZrCl}_{4},>99.95 \%$, Strem, Newburyport, MA, USA) as metal precursors, whereby $\mathrm{O}_{3}$ and $\mathrm{H}_{2} \mathrm{O}$ as oxygen precursors were used together with $\mathrm{SnI}_{4}$ and $\mathrm{ZrCl}_{4}$, respectively. $\mathrm{N}_{2}$ $(99.999 \%)$ was used as the carrier and purge gas. $\mathrm{SnI}_{4}$ was evaporated at $104 \pm 2{ }^{\circ} \mathrm{C}$ and $\mathrm{ZrCl}_{4}$ at $156 \pm 2{ }^{\circ} \mathrm{C}$ from open boats inside the reactor and transported to the substrates by the carrier gas flow. During the deposition, the chamber pressure remained in the range of 210-230 Pa. The precursor pulse durations and purge lengths for $\mathrm{SnO}_{2}$ were 5-2-5-5 s and for $\mathrm{ZrO}_{2}$ was 4-3-2-5 s, denoting the sequences of metal precursor pulse- $-\mathrm{N}_{2}$ purge$\mathrm{H}_{2} \mathrm{O} / \mathrm{O}_{3}$ pulse- $\mathrm{N}_{2}$ purge. $\mathrm{SnO}_{2}-\mathrm{ZrO}_{2}$ layered nanostructures were deposited in the following manner: $60 \times \mathrm{SnO}_{2}\left(60 \mathrm{ALD}\right.$ growth cycles of $\left.\mathrm{SnI}_{4}+\mathrm{O}_{3}\right)+150 \times \mathrm{ZrO}_{2}(150 \mathrm{ALD}$ growth cycles of $\mathrm{ZrCl}_{4}+\mathrm{H}_{2} \mathrm{O}$ ). Alternatively, the order of layers was reversed from $\mathrm{SnO}_{2}$ $\mathrm{ZrO}_{2}$ to $\mathrm{ZrO}_{2}-\mathrm{SnO}_{2}$. The reference samples of 120 cycles $\mathrm{SnO}_{2}$ and 300 cycles $\mathrm{ZrO}_{2}$ were also prepared, grown to the comparable thicknesses. All the films were deposited on silicon (100) substrates at $300^{\circ} \mathrm{C}$. Prior to the deposition, the substrates were degreased in the hot mixture of $\mathrm{H}_{2} \mathrm{SO}_{4}-\mathrm{H}_{2} \mathrm{O}_{2}$, followed by etching in a $\mathrm{HF}$ solution to remove the native oxide, and rinsed in deionized water. 
The crystal structure was evaluated by grazing incidence X-ray diffractometry (GIXRD), by using a SmartLab (Rigaku, Tokyo, Japan) tool with the incidence angle of $0.42 \mathrm{deg}$ and the $\mathrm{CuK} \alpha$ radiation, which corresponds to an X-ray wavelength of $0.154063 \mathrm{~nm}$. The morphology of the layered structures on Si substrate was investigated by scanning electron microscopy (SEM) by using Helios Nanolab 600 DualBeam (FIB) microscope.

The hardness and Young's modulus of the films were determined using an instrumented nanoindentation of Bruker's TriboIndenter T1980 (Eden Prairie, MN, USA). The Berkovich tip was calibrated prior to the measurements on a fused quart glass reference sample with a hardness of $9.25 \mathrm{GPa}$ and a reduced modulus of $69.6 \mathrm{GPa}$. The standard deviation for hardness and modulus were 0.46 and 1.85 , respectively, in the displacement range from 5 to $50 \mathrm{~nm}$. Indentation was carried out in both quasi and dynamic (continuous stiffness measurement) modes with forces varying from 50 to $250 \mu \mathrm{N}$. In addition, the indents were characterized by the scanning probe microscopy (SPM) method applied by the same TriboIndenter and refined with open software Gwyddion 2.56. Displacement regions where the measured values matched with the properties of the fused quartz glass were calibrated (Figure 1) and could, thereafter, be regarded as the trustworthy indentation range.

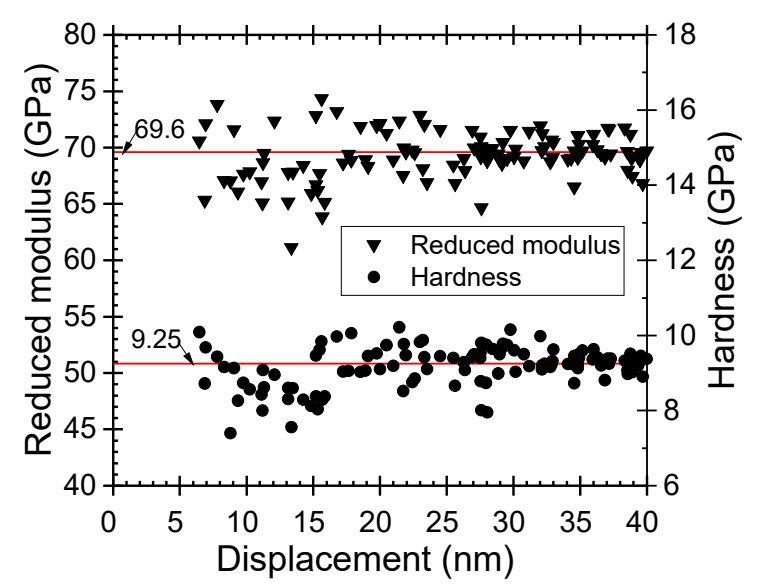

Figure 1. Nanoindentation tip calibration results for reduced elastic modulus and hardness against indentation depth. Solid horizontal lines indicate the reference values of $69.6 \mathrm{GPa}$ and $9.25 \mathrm{GPa}$, for the modulus and hardness, respectively, characteristic of fused quartz.

Selected films were subjected to magnetic measurements performed by using the P525 Vibrating Sample Magnetometer (VSM) option of the Physical Property Measurement System (PPMS) 14T (Quantum Design). Rectangular samples (about $5 \times 5 \mathrm{~mm}^{2}$ ) were fixed with GE 7031 varnish to the commercial quartz sample holders (Quantum Design). Hysteresis measurements were carried out at room temperature $(300 \mathrm{~K})$ by scanning the magnetic field from $-40,000$ to $+40,000$ Oe (from -3183.098 to $3183.098 \mathrm{kA} / \mathrm{m}$ ) parallel to the film surface. The diamagnetic signal, arising from the silicon substrate, was subtracted from the general magnetization curve for all samples in which the ferromagnetic-like response was detected.

\section{Film Structure and Morphology}

The films were grown to thicknesses not exceeding $25 \mathrm{~nm}$. Such rather thin and expectedly nanocrystalline stacked layers were built as those being of interest in terms of magnetic nanostructures. At the same time, the low thickness of the stacked layers was also expected to create challenges in the evaluation of mechanical properties using instrumented nanoindentation. The films were grown on silicon as well as on metal oxide substrates. Average growth rates for the $\mathrm{SnO}_{2}$ and $\mathrm{ZrO}_{2}$ films at $300{ }^{\circ} \mathrm{C}$ were 0.21 and $0.07 \mathrm{~nm} /$ cycle, respectively, as estimated on the basis of ex-situ XRR measurements. The thicknesses and densities of the layered nanostructures are presented in Table 1. 
Table 1. Thickness, density, and roughness values of representative nanolayered thin films obtained by X-ray reflection measurements.

\begin{tabular}{|c|c|c|c|c|}
\hline & $\mathrm{SnO}_{2}$ & $\mathrm{ZrO}_{2}$ & $\mathrm{ZrO}_{2}$ & $\mathrm{SnO}_{2}$ \\
\hline & $\mathrm{ZrO}_{2}$ & $\mathrm{SnO}_{2}$ & $\mathrm{ZrO}_{2}$ & $\mathrm{SnO}_{2}$ \\
\hline & $\mathrm{Si}$ & $\mathrm{Si}$ & $\mathrm{Si}$ & $\mathrm{Si}$ \\
\hline $\begin{array}{l}\text { Description of the Given } \\
\text { Layered Nanostructures }\end{array}$ & $\mathrm{SnO}_{2} / \mathrm{ZrO}_{2} / \mathrm{Si}$ & $\mathrm{ZrO}_{2} / \mathrm{SnO}_{2} / \mathrm{Si}$ & $\mathrm{ZrO}_{2} / \mathrm{Si}$ & $\mathrm{SnO}_{2} / \mathrm{Si}$ \\
\hline Thickness, nm & $\begin{array}{l}14.9(4) / 10.4(3) \\
\text { Total } 25.3 \mathrm{~nm}\end{array}$ & $\begin{array}{l}11.4(2) / 10.1(9) \\
\text { Total } 21.5 \mathrm{~nm}\end{array}$ & $21.0(2)$ & $24.9(2)$ \\
\hline Density, $\mathrm{g} / \mathrm{cm}^{3}$ & $7.02 / 5.82$ & $5.68 / 6.80$ & 5.68 & 6.95 \\
\hline Roughness, nm & $1.2(4)$ & $1.7(2)$ & $2.1(1)$ & $1.4(8)$ \\
\hline
\end{tabular}

Scanning electron microscope images (Figure 2) demonstrated that the surfaces of both tin and zirconium oxide films were quite uniformly covered by grain-like features. Those features were slightly different, i.e., in the case of the tin oxide, the grains appeared round-like (Figure 2a,b) whereas, in the case of the zirconium oxide, the features visible on the surface were formed more like triangles (Figure $2 c, d$ ). These surface features could be connected to crystallization already after the primary visual inspection. These features indicated that the deposition temperature of $300^{\circ} \mathrm{C}$ was high enough to initiate crystal growth in both oxide layers grown to thicknesses as low as 10-15 nm.

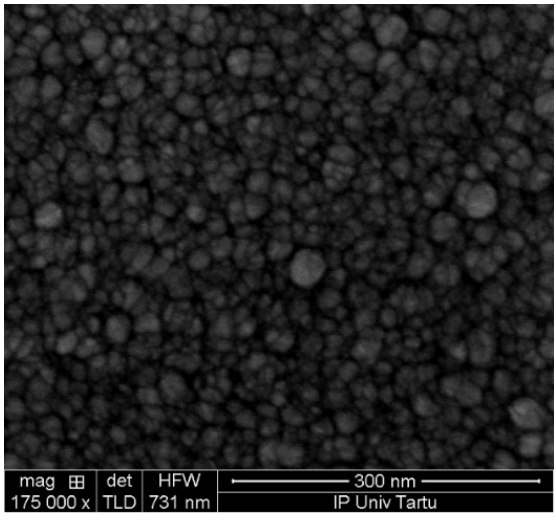

(a)

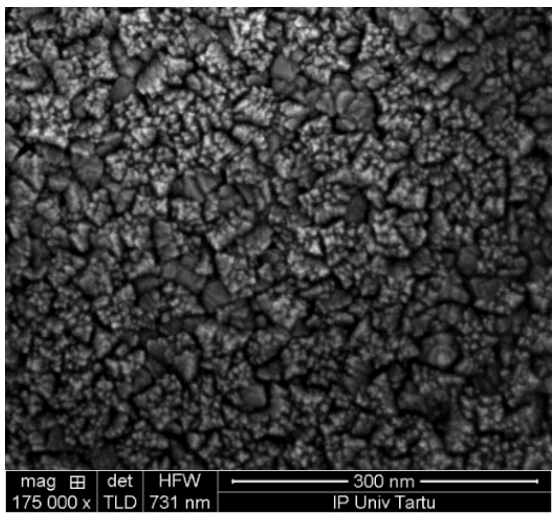

(c)

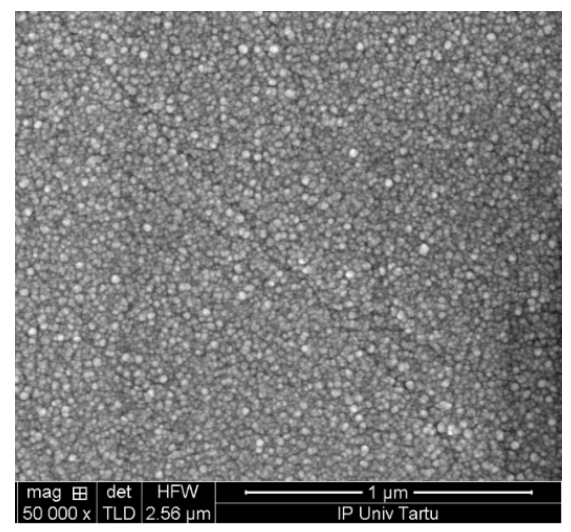

(b)

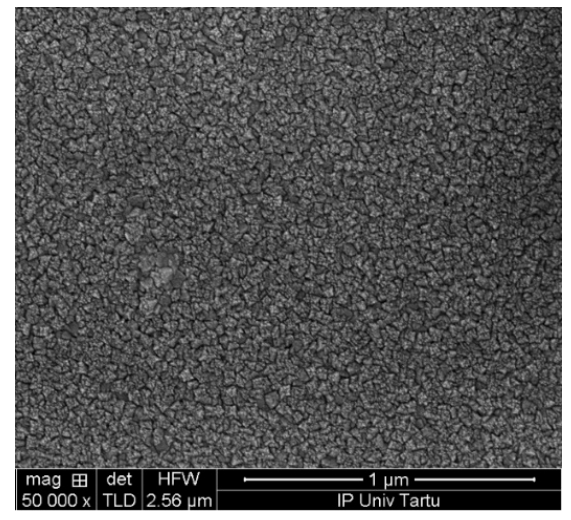

(d)

Figure 2. Scanning electron microscope bird-eye images of top $\mathrm{SnO}_{2}(\mathbf{a}, \mathbf{b})$ and $\mathrm{ZrO}_{2}(\mathbf{c}, \mathbf{d})$ layers in stacked nanostructures. 
The GIXRD patterns confirmed that all the double-layered nanostructures were indeed crystallized already in the as-deposited state. The diffractogram of the reference $\mathrm{ZrO}_{2}$ thin film (Figure 3 , topmost pattern) revealed clear peaks at $30.7^{\circ}, 34.9^{\circ}, 43.6^{\circ}, 50.8^{\circ}, 59.7^{\circ}$, and $60.7^{\circ}$, attributable to those of $011,002 / 110,012,112 / 020,013$, and 121 reflections respectively, of the tetragonal $\mathrm{ZrO}_{2}$ phase (PDF card 00-050-1089). The diffractogram of the reference $\mathrm{SnO}_{2}$ thin film (Figure 3, the lowest pattern) revealed at $26.9^{\circ}, 38.8^{\circ}$, and $52.6 / 54.5^{\circ}$, attributable to those of 110,111 , and $211 / 220$ reflections respectively, of the tetragonal $\mathrm{SnO}_{2}$ phase (PDF card 00-041-1445). Relatively weak reflections of the orthorhombic phase of $\mathrm{SnO}_{2}$ were also observed in the case of films containing tin oxide layer at $25.0^{\circ}, 34.3^{\circ}, 52.3^{\circ}, 62.7^{\circ}$, and $66.3^{\circ}$, attributable to $101,002,202,221,023$, and 132 reflections, orthorhombic $\mathrm{SnO}_{2}$ phase (PDF Card 00-029-1484). The common phase for $\mathrm{SnO}_{2}$, also in the thin film form, is tetragonal cassiterite, whereas the orthorhombic phase of $\mathrm{SnO}_{2}$ could become the stable one at high pressures and temperatures. Referring to earlier studies, pulsed laser deposition of metastable orthorhombic $\mathrm{SnO}_{2}$ films with improved optically transparency has been carried out on $\mathrm{Si}(100)$ substrates at $320^{\circ} \mathrm{C}[20]$ and the stabilization of that phase has been attributed to the presence and exchange reactions of oxygen vacancies at nanocrystallite boundaries in the growing films. Epitaxial orthorhombic $\mathrm{SnO}_{2}$ films have been grown on stabilized cubic $\mathrm{ZrO}_{2}: \mathrm{Y}$ films by metal-organic chemical vapor deposition from tetraethyltin, $\mathrm{Sn}\left(\mathrm{C}_{2} \mathrm{H}_{5}\right)_{4}$, and $\mathrm{O}_{2}$ at 500 and $600{ }^{\circ} \mathrm{C}$ [21]. Considering possible intermixing of solid layers and formation of ternary compounds, orthorhombic $\mathrm{ZrSnO}_{4}$ phase has been observed previously in calcined nanocomposites of $\mathrm{ZrO}_{2}$ and $\mathrm{SnO}_{2}$ prepared by sol-gel technique [22], but reflections of such ternary compounds were not observed in the present study. Thus, the constituent oxides must have grown on top of each other and formed nanocrystalline stacks of two different components.

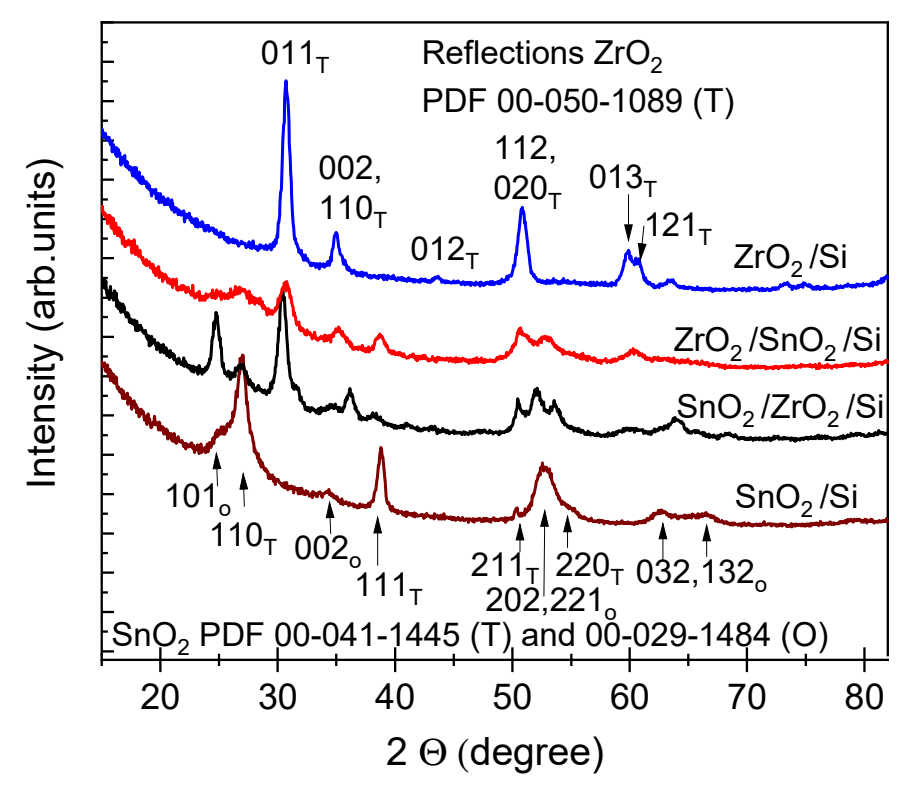

Figure 3. X-ray diffraction patterns from the $\mathrm{SnO}_{2}$ and $\mathrm{ZrO}_{2}$ thin films and $\mathrm{ZrO}_{2}-\mathrm{SnO}_{2}$ stacked layered nanostructures, in the as-deposited state of thin films. Miller indexes assigned after crystallization are indicated with " $\mathrm{T}$ " for the tetragonal phase of $\mathrm{ZrO}_{2}$, " $\mathrm{T}$ " and "O" for the tetragonal and orthorhombic phases of the $\mathrm{SnO}_{2}$ accordingly.

\section{Mechanical Properties}

The nanoindentation results are presented in Table 2, where the geometric mean values for hardness and Young's modulus are given for each film. Thereby, the $21 \mathrm{~nm}$ thick $\mathrm{ZrO}_{2} / \mathrm{Si}$ film possessed the hardness of $11.5 \mathrm{GPa}$ and elastic modulus of $96 \mathrm{GPa}$, which are slightly lower values than those measured in approximately three times thicker films deposited earlier in a similar ALD process [23,24]. The $25 \mathrm{~nm}$ thick $\mathrm{SnO}_{2} / \mathrm{Si}$ film possessed noticeably 
higher hardness and stiffness than that based on the $\mathrm{ZrO}_{2}$. For the $\mathrm{ZrO}_{2}-\mathrm{SnO}_{2}$ stacked nanostructures, the order of layers has influenced the mechanical properties (Figure 4). For the layers stacked with the harder and stiffer $\mathrm{SnO}_{2}$ on top of $\mathrm{ZrO}_{2}$, the hardness and Young's modulus of the stack resembled those of the $\mathrm{SnO}_{2}$ film (Figure 4a). At the same time, when the $\mathrm{SnO}_{2}$ layer was deposited first, below the $\mathrm{ZrO}_{2}$, the mechanical properties of the stack started to resemble those of the $\mathrm{ZrO}_{2}$ film (Figure $4 \mathrm{~b}$ ). The substrate was characterized by the hardness similar to that of the softer oxide films, and the average elastic modulus remaining between those of the harder and softer oxide films (Figure 5).

Table 2. Descriptive statistics of nanoindentation results (SD standard deviation).

\begin{tabular}{ccccc}
\hline Sample & $\begin{array}{c}\text { Hardness (GPa) } \\
\text { Geometric } \\
\text { Mean } \pm \text { SD }\end{array}$ & $\begin{array}{c}\text { Hardness (GPa) } \\
\text { Range }\end{array}$ & $\begin{array}{c}\text { Young's } \\
\text { Modulus (GPa) } \\
\text { Geometric } \\
\text { Mean } \pm \text { SD }\end{array}$ & $\begin{array}{c}\text { Young's } \\
\text { Modulus (GPa) } \\
\text { Range }\end{array}$ \\
\hline $\mathrm{ZrO}_{2} / \mathrm{Si}$ & $11.5 \pm 1.1$ & $7.7-13.5$ & $96 \pm 1$ & $84-119$ \\
$\mathrm{SnO}_{2} / \mathrm{Si}$ & $14.8 \pm 1.1$ & $12.0-18.8$ & $175 \pm 1$ & $142-229$ \\
$\mathrm{ZrO}_{2} / \mathrm{SnO}_{2} / \mathrm{Si}$ & $10.8 \pm 1.1$ & $7.5-15.3$ & $72 \pm 1$ & $62-89$ \\
$\mathrm{SnO}_{2} / \mathrm{ZrO}_{2} / \mathrm{Si}$ & $15.1 \pm 1.1$ & $11.6-20.0$ & $171 \pm 1$ & $143-205$ \\
$\mathrm{Si}$ & $10.8 \pm 1.2$ & $7.5-14.0$ & $133 \pm 1$ & $108-167$ \\
\hline
\end{tabular}

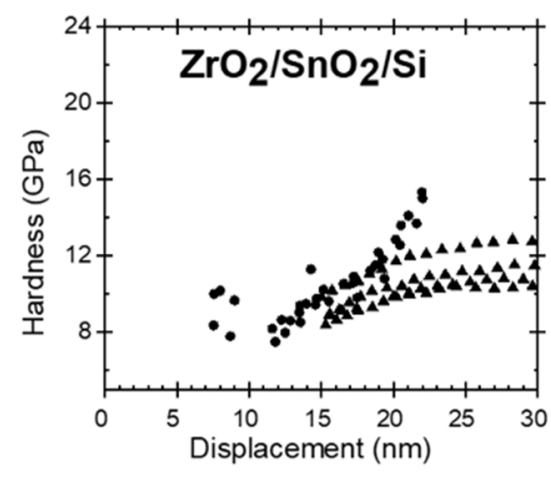

(a)

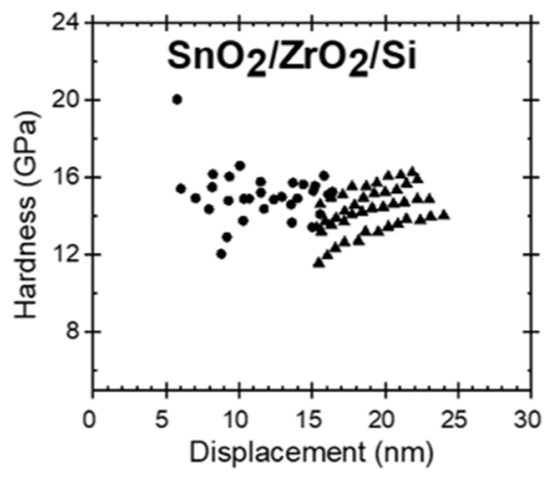

(b)

Figure 4. Hardness along the depth of the $\mathrm{ZrO}_{2} / \mathrm{SnO}_{2} / \mathrm{Si}$ (a) and $\mathrm{SnO}_{2} / \mathrm{ZrO}_{2} / \mathrm{Si}$ (b) stacked layered nanostructures. Results of quasi-static indentation measurements $(\bullet)$ and dynamic measurements $(\boldsymbol{\Delta})$.

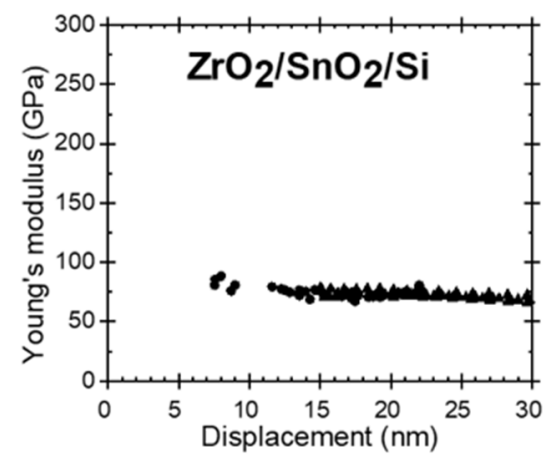

(a)

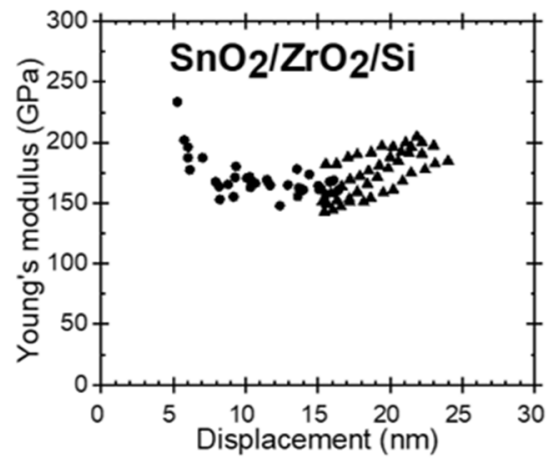

(b)

Figure 5. Young's modulus along the depth of the $\mathrm{ZrO}_{2} / \mathrm{SnO}_{2} / \mathrm{Si}$ (a) and $\mathrm{SnO}_{2} / \mathrm{ZrO}_{2} / \mathrm{Si}$ (b) stacked layered nanostructures. Results of quasi-static indentation measurements $(\bullet)$ and dynamic measurements $(\boldsymbol{\Lambda})$.

The nanoindentation measurements are presented in Figures 4 and 5. Neither hardness nor elastic modulus seemed to change at different depths. The likely influence of 
the substrate did not become evident during the indentation measurement procedures. However, considering the film thicknesses and the measured depth ranges, the results should be influenced by the substrate. The films were grown to thicknesses less than $30 \mathrm{~nm}$, and at indentation depths exceeding $10 \%$ of the film thickness the effect of the substrate must become significant $[25,26]$.

The initial work of Jönsson and Hogmark [27] states that the substrate starts to influence the coating-substrate measurement results when the indentation displacements are around $0.07-0.2$ times the coating thickness. Therefore, it became evident that specific models have to be developed to find the properties of the coating alone. Over the years, several researchers have proposed different models to perform such calculations, in addition to Jöhnsson and Hogmark, for instance, Burnett and Rickerby [28], Chicot and Lesage [29], and Tuck and Korsunsky [30]. In one of the latest works, written by Puchi-Cabrera, a comprehensive comparison of named models and an additional model is proposed [31]. The problem with the calculation of the sole coating property is that the coatings are never used as a single piece of material but it covers some other material and therefore the performance is usually the combination of the two. Therefore, it is rather reasonable to create a specific coating-substrate system with emphasis on a probable application and then characterize the stack as a whole. Therefore, any attempt to calculate the sole property of the deposited thin films is omitted here.

The results obtained in separate measurements were considerably scattered (Table 2). This can be attributed to the complications with the calibration of the indenter tips within small displacements, heterogeneity, and anisotropy of the measured materials [25], or the absence of considerable plastic deformation at such low indentation loads. Hardness can be determined when plastic deformation occurs, whereas, during the measurements in the present study, one had to apply forces weaker than those required to produce sufficient extents of plastic deformation. Figure 6 shows the SPM images of the indents and the corresponding load-displacement graphs (Figure 6a) with a maximum indentation force of $135 \mu \mathrm{N}$. At this indentation load (in the quasi mode) the indentation depth of the film $\mathrm{SnO}_{2}$ is comparable to the surface roughness in Table 1 (Figure 6b). Decreasing the indentation load diminished the discernibility of the indents further, meaning that little or no plastic deformation occurred, making the hardness, estimated at applied loads smaller than $135 \mu \mathrm{N}$, unreliable. The average hardness presented in Table 2 was calculated using results acquired at higher loads and from dynamic measurements.

The mechanical properties of the stacked films were influenced significantly by the order of the layers. A theoretical study by Pelegri et al. [26] on the behavior of hardness and Young modulus in hard-film-soft-substrate and soft-film-hard-substrate systems indicated tendencies somewhat similar to the results obtained in the present study. In the present study, for the nanostructures with the top $\mathrm{ZrO}_{2}$ (softer) layer and bottom $\mathrm{SnO}_{2}$ (harder) layer, the hardness was similar to that of the $\mathrm{ZrO}_{2}$ film. However, the Young modulus of such nanostructure was slightly lower compared to the $\mathrm{ZrO}_{2}$ reference film which could be due to the influence of the $\mathrm{Si}$ substrate that has lower stiffness than $\mathrm{SnO}_{2}$. Pelegri et al. [26] found that the hard-film-soft-substrate system should possess the same hardness as the hard-bulk material, yet lower Young modulus. In the present study, the $\mathrm{SnO}_{2} / \mathrm{ZrO}_{2} / \mathrm{Si}$ system was measured by the same hardness as $\mathrm{SnO}_{2} / \mathrm{Si}$, and also similar modulus which again could be the result of the influence of the $\mathrm{Si}$ substrate $[27,30,31]$. 

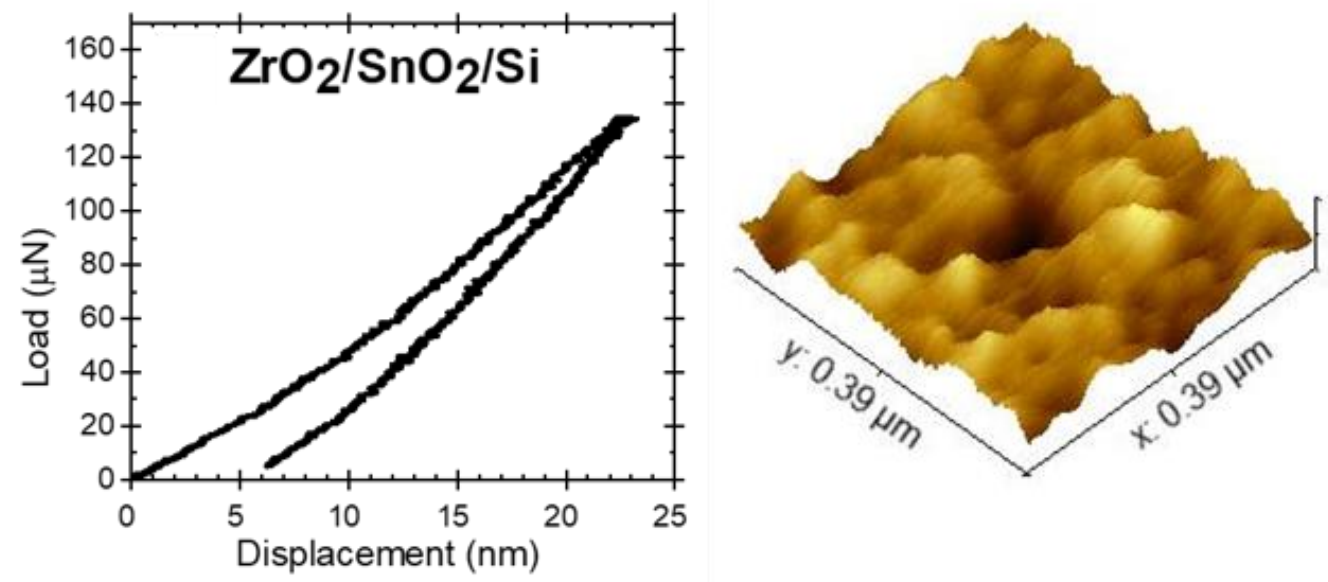

$1.9 \mathrm{~nm}$
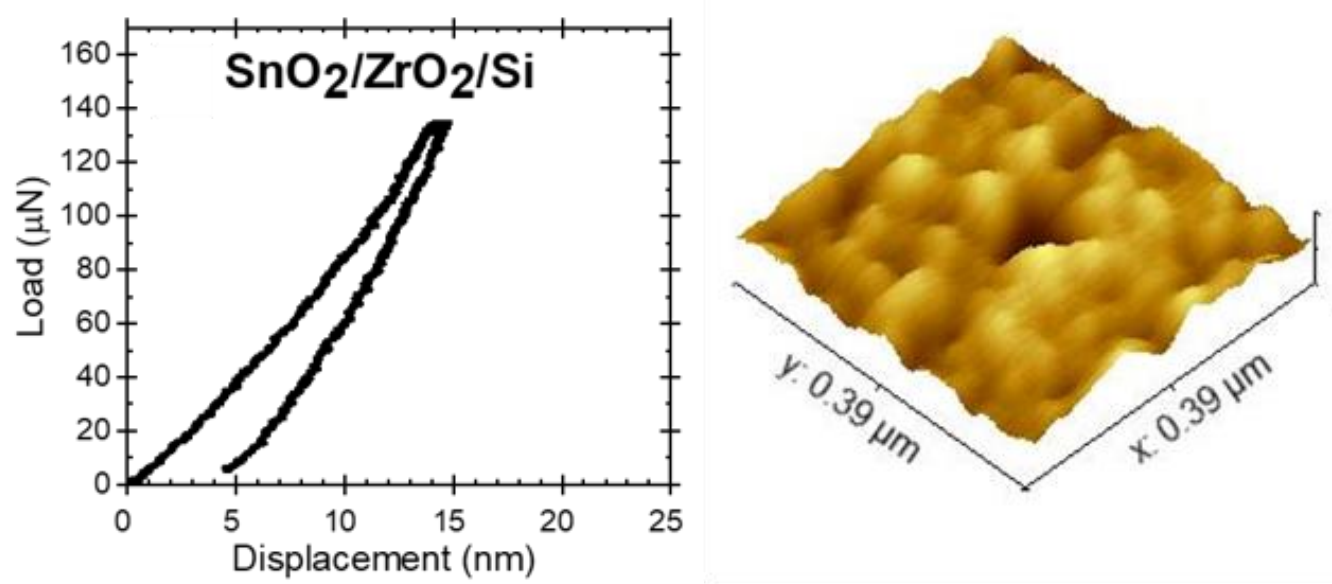

$2.2 \mathrm{~nm}$

$-4.3 \mathrm{~nm}$

Figure 6. The load-displacement curves (a) and scanning probe microscopy images (b) of the $\mathrm{ZrO}_{2} / \mathrm{SnO} \mathrm{Sn}_{2} / \mathrm{Si}(\mathbf{a})$ and $\mathrm{SnO}_{2} / \mathrm{ZrO}_{2} / \mathrm{Si}(\mathbf{b})$ stacked layered nanostructures. The corresponding load-displacement curves produced the indents with a maximum load of $135 \mu \mathrm{N}$.

\section{Magnetic Properties}

Magnetic measurements were performed for as-deposited stacked nanostructures by applying a magnetic field in the film plane. The structures demonstrated at room temperature nonlinear hysteretic magnetization, generally characteristic to ferromagnetic, ferrimagnetic, and superparamagnetic materials, at room temperature with saturation magnetization (Figure 7a). In the magnetization-field (M-H) curves, the saturation magnetization values for the $\mathrm{SnO}_{2} / \mathrm{ZrO}_{2} / \mathrm{Si}$ and $\mathrm{ZrO}_{2} / \mathrm{SnO}_{2} / \mathrm{Si}$ nanostructures reached $1.5 \times 10^{-4}$ and $3.5 \times 10^{-4} \mathrm{emu}$, respectively. Both double-layered nanostructures showed measurable coercivity, ranging approximately from 65 to 130 Oe (5.2 to $10.4 \mathrm{kA} / \mathrm{m})$. The saturation magnetization $\mathrm{M}_{\mathrm{s}}$, recorded at $1 \mathrm{kOe}$ against temperature (Figure $7 \mathrm{~b}$ ), followed a linear trend, decreasing moderately with increasing temperature. Single $\mathrm{ZrO}_{2}$ film on Si substrate exhibited magnetization lower than $2 \times 10^{-6} \mathrm{emu}$ and insignificant coercivity, which is also consistent with the results of our earlier studies [32]. However, single $\mathrm{ZrO}_{2}$ films, grown to higher thicknesses, otherwise can exhibit considerable hysteretic magnetization, nonlinear in external fields, as has been observed in several works earlier [33-35], probably due to the stabilization and presence of metastable phases, rich of oxygen vacancies. The latter inevitably accompanies the nanocrystalline nature of the thin solid structures and concurrent stabilization of metastable polymorphs. The role of vacancies as likely the main factor affecting the surface energies and inducing stabilization of metastable polymorphs in nanocrystalline $\mathrm{ZrO}_{2}$ has earlier been studied and is a widely recognized phenomenon [36-40]. Magnetic properties may, in a somewhat similar manner, appear and become measurable in $\mathrm{SnO}_{2}$ based oxide films. The room temperature ferromagnetism has 
been detected in $\mathrm{SnO}_{2}$-based nanostructures not mixed with foreign cations, as reported in several papers [41-44].

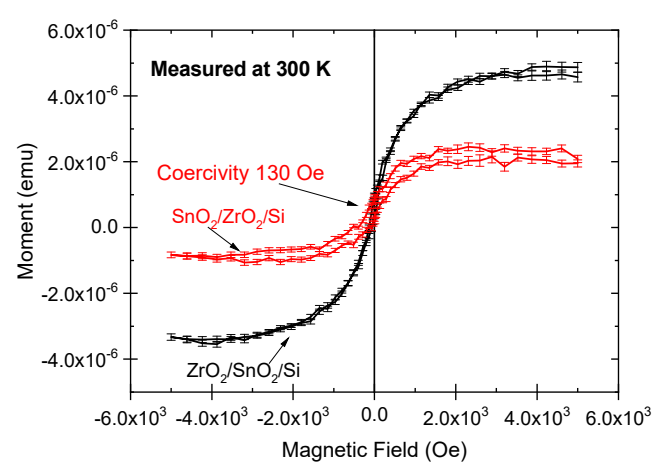

(a)

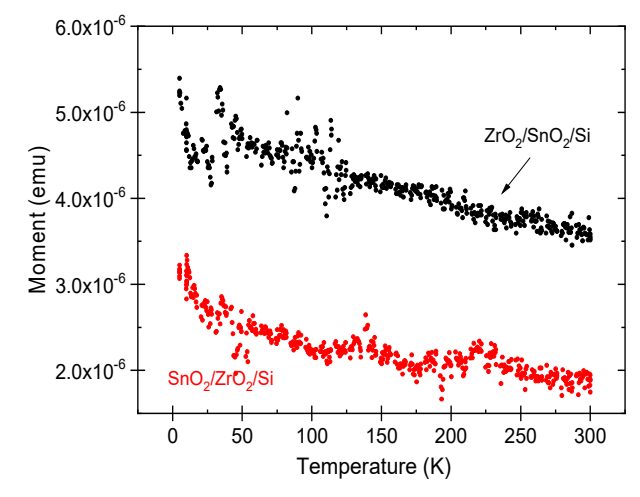

(b)

Figure 7. Magnetization versus external field curves measured at room temperature (a) and temperature dependencies of magnetization, recorded at $1 \mathrm{kOe}(\mathbf{b})$, in stacked layers of $\mathrm{SnO}_{2}$ and $\mathrm{ZrO}_{2}$, as denoted by labels.

\section{Conclusions}

$\mathrm{SnO}_{2}$ and $\mathrm{ZrO}_{2}$ stacked double-layered nanostructures were deposited by atomic layer deposition using $\mathrm{SnI}_{4}, \mathrm{ZrCl}_{4}, \mathrm{O}_{3}$, and $\mathrm{H}_{2} \mathrm{O}$. Layered structures consisting of chemically distinct metal oxide layers were formed at a substrate temperature of $300{ }^{\circ} \mathrm{C}$ on silicon substrates. The $\mathrm{ZrO}_{2}$ and $\mathrm{SnO}_{2}$ layers contained complementary and presumably oxygendeficient metastable phases, as indicated by the presence of reflections from tetragonal and orthorhombic polymorphs, respectively, in their X-ray diffraction patterns.

The films were grown to comparable thicknesses in the range of $20-25 \mathrm{~nm}$. Evaluation of their mechanical behavior indicated that the properties could be approximated to those of sequentially stacked hard and soft layers, and vice versa, on monocrystalline silicon. Both hardness and elasticity of the double layers essentially depended on the order of constituent oxide films of different durability. The $\mathrm{ZrO}_{2} / \mathrm{SnO}_{2} / \mathrm{Si}$ stacks with $\mathrm{ZrO}_{2}$ top layers could be characterized with a hardness of 11 and elastic modulus of $72 \mathrm{GPa}$, whereas in the $\mathrm{SnO}_{2} / \mathrm{ZrO}_{2} / \mathrm{Si}$ stacks, the corresponding values reached 15 and $171 \mathrm{GPa}$.

The double-layered nanostructures exhibited magnetization behavior characteristic of ferro-, ferri-, or paramagnetic materials, i.e., nonlinear and reaching saturation in external magnetic fields. The $\mathrm{ZrO}_{2} / \mathrm{SnO}_{2} / \mathrm{Si}$ stacks possessed higher magnetization values compared to those in the $\mathrm{SnO}_{2} / \mathrm{ZrO}_{2} / \mathrm{Si}$ stacks, but the latter films demonstrated stronger coercive force, 130 versus $65 \mathrm{Oe}$. Such studies may add to the knowledge on the synthesis and characterization of wide-band-gap, and thereby optically transparent, metal oxidebased composites as mechanically tough and, at the same time, magnetically susceptible thin films.

Author Contributions: Conceptualization, A.T. (Aile Tamm); methodology, T.J.; investigation, H.M.P., A.T. (Aivar Tarre) and J.L.; resources, A.T. (Aile Tamm) and R.S.; writing-Original draft preparation, A.T. (Aile Tamm); writing-Review and editing, A.T. (Aile Tamm), K.K. and R.S.; funding acquisition, A.T. (Aile Tamm). All authors have read and agreed to the published version of the manuscript.

Funding: The present study was partially funded by the European Regional Development Fund project "Emerging orders in quantum and nanomaterials" (TK134) and Estonian Research Agency (PRG4 and PRG753). This work was partially supported by European Regional Development Fund project "Centre of nanomaterials technologies and research" (NAMUR+, Project No. 20142020.4.01.16-0123).

Institutional Review Board Statement: Not applicable. 
Informed Consent Statement: Not applicable.

Data Availability Statement: Not applicable.

Conflicts of Interest: The authors declare no conflict of interest.

\section{References}

1. Kobayashi, N.; Masumoto, H.; Takahashi, S.; Maekawa, S. Optically transparent ferromagnetic nanogranular films with tunable transmittance. Sci. Rep. 2016, 6, 34227. [CrossRef]

2. Sheng, P.; Wang, B.; Li, R. Flexible magnetic thin films and devices. J. Semicond. 2018, 39, 011006. [CrossRef]

3. Schiavone, G.; Desmulliez, M.P.Y.; Walton, A.J. Integrated magnetic MEMS relays: Status of the technology. Micromachines 2014, 5, 622-653. [CrossRef]

4. Niarchos, D. Magnetic MEMS: Key issues and some applications. Sens. Actuators 2003, 109, 166-173. [CrossRef]

5. Foerster, M.; Menéndez, E.; Coy, E.; Quintana, A.; Gómez-Olivella, C.; de los Ojos, D.E.; Vallcorba, O.; Frontera, C.; Aballe, L.; Nogués, J.; et al. Local manipulation of metamagnetism by strain nanopatterning. Mater. Horiz. 2020, 7, 2056-2062. [CrossRef]

6. Sort, J.; Concustell, A.; Menéndez, E.; Suriñach, S.; Baró, M.D.; Farran, J.; Nogués, J. Selective generation of local ferromagnetism in austenitic stainless steel using nanoindentation. Appl. Phys. Lett. 2006, 89, 032509. [CrossRef]

7. Zhou, H.; Pei, Y.; Fang, D. Magnetic Field Tunable Small-scale Mechanical Properties of Nickel Single Crystals Measured by Nanoindentation Technique. Sci. Rep. 2014, 4, 4583. [CrossRef]

8. Papakonstantinou, P.; Lemoine, P.; McLaughlin, J.; MacKay, K.; Dodd, P.M.; Pollard, R.J.; Atkinson, R. Nanoindentation studies of FeXN (X = Ta, Ti) soft magnetic films. J. Appl. Phys. 2000, 87, 6170. [CrossRef]

9. Baco, S.; Abbas, Q.A.; Hayward, T.J.; Morley, N.A. An investigation on the mechanical properties of soft magnetostrictive FeCoCr films by nanoindentation. J. Alloys Comp. 2021, 881, 160549. [CrossRef]

10. Lee, J.; Nagarajan, G.S.; Shon, Y.; Kwon, Y.; Kang, T.W.; Kim, D.Y.; Kim, H.; Im, H.; Park, C.-S.; Kim, E.K. Room temperature transparent conducting magnetic oxide (TCMO) properties in heavy ion doped oxide semiconductor. AIP Adv. 2017, 7, 085114. [CrossRef]

11. Ginley, D.S.; Bright, C. Transparent conducting oxides. MRS Bull. 2000, 25, 15-18. [CrossRef]

12. Batzill, M.; Diebold, U. The surface and materials science of tin oxide. Prog. Surf. Sci. 2005, 79, 47-154. [CrossRef]

13. Çetinörgü, E.; Goldsmith, S. Chemical and thermal stability of the characteristics of filtered vacuum arc deposited $\mathrm{ZnO}_{2} \mathrm{SnO} \mathrm{O}_{2}$ and zinc stannate thin films. J. Phys. D Appl. Phys. 2007, 40, 5220-5226. [CrossRef]

14. Qadri, S.B.; Kim, U.H.; Khan, H.R.; Pique, A.; Horwitz, J.S.; Chrisey, D.; Kim, W.J.; Skelton, E.F. Transparent conducting films of $\mathrm{In}_{2} \mathrm{O}_{3}-\mathrm{ZrO}_{2}, \mathrm{SnO}_{2}-\mathrm{ZrO}_{2}$ and $\mathrm{ZnO}-\mathrm{ZrO}_{2}$. Thin Solid Films 2000, 377-378, 750-754. [CrossRef]

15. Jang, J.; Kitsomboonloha, R.; Swisher, S.L.; Park, E.S.; Kang, H.; Subramanian, V. Transparent high-performance thin film transistors from solution-processed $\mathrm{SnO}_{2} / \mathrm{ZrO}_{2}$ gel-like precursors. Adv. Mater. 2013, 25, 1042-1047. [CrossRef]

16. Manjula, N.; Selvan, G. Magnetic and antibacterial properties of Zr-doped $\mathrm{SnO}_{2}$ nanopowders. J. Mater. Sci. Mater. Electron. 2017, 28, 15056-15064. [CrossRef]

17. Aarik, J.; Aidla, A.; Mändar, H.; Uustare, T.; Sammelselg, V. Growth kinetics and structure formation of $\mathrm{ZrO}_{2}$ thin films in chloride-based atomic layer deposition process. Thin Solid Films 2002, 408, 97-103. [CrossRef]

18. Alnes, M.E. Transparent Conducting Oxides by Atomic Layer Deposition. Ph.D. Thesis, University of Oslo, Oslo, Norway, 2014. Available online: https:/ / www.duo.uio.no/handle/10852/48768 (accessed on 24 April 2021).

19. Arroval, T.; Aarik, L.; Rammula, R.; Kruusla, V.; Aarik, J. Effect of substrate-enhanced and inhibited growth on atomic layer deposition and properties of aluminum-titanium oxide films. Thin Solid Films 2016, 600, 119-125. [CrossRef]

20. Chen, Z.; Lai, J.K.L.; Shek, C.-H. Facile strategy and mechanism for orthorhombic $\mathrm{SnO}_{2}$ thin films. Appl. Phys. Lett. 2006, 89, 231902. [CrossRef]

21. Kong, L.; Ma, J.; Zhu, Z.; Luan, C.; Yu, X.; Yu, Q. Synthesis of orthorhombic structure epitaxial tin oxide film. Mater. Lett. 2010, 64, 1350-1353. [CrossRef]

22. Joy, K.; Lakshmy, S.S.; Thomas, P.V. Band gap tuning in nanocomposite $\mathrm{ZrO}_{2}-\mathrm{SnO}_{2}$ thin film achieved through sol-gel codeposition method. J. Sol Gel Sci. Technol. 2012, 61, 179-184. [CrossRef]

23. Jõgiaas, T.; Kull, M.; Seemen, H.; Ritslaid, P.; Kukli, K.; Tamm, A. Optical and mechanical properties of nanolaminates of zirconium and hafnium oxides grown by atomic layer deposition. J. Vac. Sci. Technol. A 2020, 38, 022406. [CrossRef]

24. Piirsoo, H.-M.; Jõgiaas, T.; Mändar, H.; Ritslaid, P.; Kukli, K.; Tamm, A. Microstructure and mechanical properties of atomic layer deposited alumina doped zirconia. AIP Adv. 2021, 11, 055316. [CrossRef]

25. Menčík, J. Uncertainties and errors in nanoindentation. In Nanoindentation in Materials Science; Nemecek, J., Ed.; InTech Open: Rijeka, Croatia, 2012. [CrossRef]

26. Pelegri, A.A.; Huang, X. Nanoindentation on soft film/hard substrate and hard film/soft substrate material systems with finite element analysis. Comp. Sci. Technol. 2008, 68, 147-155. [CrossRef]

27. Jönsson, B.; Hogmark, S. Hardness measurements of thin films. Thin Solid Films 1984, 114, 257-269. [CrossRef]

28. Burnett, P.J.; Rickerby, D.S. The relationship between hardness and scratch adhesion. Thin Solid Films 1987, 154, $403-416$. [CrossRef]

29. Chicot, D.; Lesage, J. Absolute hardness of films and coatings. Thin Solid Films 1995, 254, 123-130. [CrossRef] 
30. Tuck, J.R.; Korsunsky, A.M.; Davidson, R.I.; Bull, S.J.; Elliott, D.M. Modelling of the hardness of electroplated nickel coatings on copper substrates. Surf. Coat. Technol. 2000, 127, 1-8. [CrossRef]

31. Puchi-Cabrera, E.S. A new model for the computation of the composite hardness of coated systems. Surf. Coat. Technol. 2002, 160, 177-186. [CrossRef]

32. Kalam, K.; Seemen, H.; Mikkor, M.; Ritslaid, P.; Stern, R.; Dueñas, S.; Castán, H.; Tamm, A.; Kukli, K. Electric and magnetic properties of atomic layer deposited $\mathrm{ZrO}_{2}-\mathrm{HfO}_{2}$ thin films. ECS J. Solid State Sci. Tech. 2018, 7, N117-N122. [CrossRef]

33. Ning, S.; Zhan, P.; Xie, Q.; Li, Z.; Zhang, Z. Room-temperature ferromagnetism in un-doped $\mathrm{ZrO}_{2}$ thin films. J. Phys. D Appl. Phys. 2013, 46, 445004. [CrossRef]

34. Rahman, M.A.; Rout, S.; Thomas, J.P.; McGillivray, D.; Leung, K.T. Defect-rich dopant-free $\mathrm{ZrO}_{2}$ nanostructures with superior dilute ferromagnetic semiconductor properties. J. Am. Chem. Soc. 2016, 138, 11896. [CrossRef]

35. Kalam, K.; Seemen, H.; Ritslaid, P.; Rähn, M.; Tamm, A.; Kukli, K.; Kasikov, A.; Link, J.; Stern, R.; Dueñas, S.; et al. Atomic layer deposition and properties of $\mathrm{ZrO}_{2} / \mathrm{Fe}_{2} \mathrm{O}_{3}$ thin films. Beilstein J. Nanotechnol. 2018, 9, 119-128. [CrossRef]

36. Lu, X.; Liang, K.; Gu, S.; Zheng, Y.; Fang, H. Effect of oxygen vacancies on transformation of zirconia at low temperatures. J. Mater. Sci. 1997, 32, 6653-6656. [CrossRef]

37. Kalita, P.; Saini, S.; Rajput, R.; Jha, S.N.; Bhattacharyya, D.; Ojha, S.; Devesh, K.; Avasthi, D.K.; Bhattacharya, S.; Ghosh, S. Oxygen vacancy mediated cubic phase stabilization at room temperature in pure nano-crystalline zirconia films: A combined experimental and first-principles based investigation. Phys. Chem. Chem. Phys. 2019, 21, 22482-22490. [CrossRef]

38. Cong, Y.; Li, B.; Yue, S.; Fan, D.; Wang, X. Effect of oxygen vacancy on phase transition and photoluminescence properties of nanocrystalline zirconia synthesized by the one-pot reaction. J. Phys. Chem. C 2009, 113, 13974-13978. [CrossRef]

39. Bai, X.-M.; Zhang, Y.; Tonks, M.R. Strain effects on oxygen transport in tetragonal zirconium dioxide. Phys. Chem. Chem. Phys. 2013, 15, 19438. [CrossRef]

40. Lamperti, A.; Lamagna, L.; Congedo, G.; Spiga, S. Cubic/tetragonal phase stabilization in high-k $\mathrm{ZrO}_{2}$ thin films grown using $\mathrm{O}_{3}$-based atomic layer deposition. J. Electrochem. Soc. 2011, 158, G221-G226. [CrossRef]

41. Chang, G.S.; Forrest, J.; Kurmaev, E.Z.; Morozovska, A.N.; Glinchuk, M.D.; McLeod, J.A.; Moewes, A.; Surkova, T.P.; Hong, N.H. Oxygen-vacancy-induced ferromagnetism in undoped $\mathrm{SnO}_{2}$ thin films. Phys. Rev. B 2012, 85, 165319. [CrossRef]

42. Dutta, D.; Bahadur, D. Influence of confinement regimes on magnetic property of pristine $\mathrm{SnO}_{2}$ quantum dots. J. Mater. Chem. 2012, 22, 24545-24551. [CrossRef]

43. Chetri, P.; Choudhury, B.; Choudhury, A. Room temperature ferromagnetism in $\mathrm{SnO}_{2}$ nanoparticles: An experimental and density functional study. J. Mater. Chem. C 2014, 2, 9294-9302. [CrossRef]

44. Sakthiraj, K.; Hema, M.; Balachandrakumar, K. Room temperature ferromagnetism of tin oxide nanocrystal based on synthesis methods. Physica B 2016, 487, 47-52. [CrossRef] 